\title{
Transforming growth factor beta-1 An important biomarker for developing cardiovascular diseases in chronic renal failure
}

\author{
Avci E ${ }^{1}$, Alp Avci G ${ }^{1}$, Ozcelik B, Coskun Cevher $\mathrm{S}^{3}$, Suicmez $\mathrm{M}^{1}$ \\ Hitit University, Faculty of Science and Arts, Department of Molecular Biology and Genetics, Corum, Turkey. \\ alp.gulcin@yahoo.com
}

\begin{abstract}
OBJECTIVE: Our study focuses on the determination and evaluation of TGF- $\beta 1$ levels of patients receiving hemodialysis treatment because of chronic renal failure.

BACKGROUND: Chronic renal failure, characterized by irreversible loss of renal function, is a major public health problem in the world. Transforming growth factor-beta is a multifunctional cytokine involved in the cellular growth, differentiation, migration, apoptosis and immune regulation. Among the three TGF- $\beta$ isoforms, TGF- $\beta 1$ plays a key role in the pathogenesis of renal diseases.

METHODS: We studied 24 patients who were on regular hemodialysis, with non-diabetic nephropathy. 20 healthy people who proved to be in a good state of health and free from any signs of chronic diseases or disorders were enrolled as a control group. Serum samples were collected both before and after hemodialysis treatment from each patient. TGF- $\beta 1$ levels were determined by Enzyme Immunoassay method.

RESULTS: TGF- $\beta 1$ levels were found significantly higher in the hemodialysis patients than those of the control groups. Also, the TGF- $\beta 1$ was significantly reduced after hemodialysis treatment but it was still higher than in control groups.

CONCLUSION: This result indicates that hemodialysis is an effective treatment method to decrease the serum TGF-B1 levels. Nevertheless, this decrease is not enough to reduce existing risks (Tab. 1, Fig. 2, Ref. 28). Text in PDF www.elis.sk.

KEY WORDS: chronic kidney disease, cardiovascular disease, hemodialysis, transforming growth factor beta.
\end{abstract}

\section{Introduction}

Chronic renal failure (CRF), characterized by irreversible loss of renal function, is emerging as a major public health problem in the world because of its increasing number of patients, high risk of progression to end-stage renal disease (ESRD), and poor prognosis of morbidity and mortality $(1,2)$. The increase in prevalence of CRF was showed by an analysis of survey data from a representative sample of the United States population (3). Reports from the United States Renal Data System highlight that the number of patients requiring renal replacement therapy with either dialysis or transplantation has increased dramatically from 209,000 in 1991 to 472,000 in 2004 (4). Hemodialysis is one of the most common treatment methods used regularly approximately all over the world $(5,6)$. On the other hand, morbidity and mortality due to vascular dysfunction associated with hemodialysis and hospital

${ }^{1}$ Hitit University, Faculty of Science and Arts, Department of Molecular Biology and Genetics, Corum, Turkey, ${ }^{2}$ Hitit University, Faculty of Science and Arts, Department of Biology, Corum, Turkey, and ${ }^{3}$ Gazi University, Faculty of Science and Arts, Department of Biology, Ankara, Turkey

Address for correspondence: G.A. Avci, Hitit University, Faculty of Science and Arts, Department of Molecular Biology and Genetics, Corum, Turkey.

Phone: +90.3642277000 , Fax: +90.3642277005 application are increased and constitutes both clinical and financial burden even for the developed and developing countries (7). Moreover, there is a significant impact of CRF on cardiovascular events and traditional CV risk factors with negative effect of tissue dysfunction, excessive oxidative stress (8). Furthermore, patients with CRF suffer from some immune disorders due to the changes of cell adhesion molecules and cytokine levels for various causes. These factors are able to induce endothelial dysfunction, lead to cardiac remodeling and hypertrophy (9). Thus, predictive role of high concentration of some inflammatory biomarkers in CRF is suggested $(10,11)$. Over the past several years, transforming growth factor beta (TGF- $\beta$ ) is a multifunctional cytokine involved in the cellular growth, differentiation and migration, formation and degradation of extracellular matrix components, chemotactic processes, and apoptosis, as well as immune regulation and has been recognized as a central mediator for the process of CRF progression $(3,12-14)$. This cytokine plays a crucial role in normal physiology and pathogenesis in a number of tissue (15). Physiological levels of TGF- $\beta$ are essential for normal development, tissue repair and maintenance of organ functions. Yet, increased TGF- $\beta$ expression has been associated with pathological alteration characteristics of various diseases such as pulmonary fibrosis, spinal muscular atrophy and renal diseases (15-17). TGF- $\beta$ levels are increased in patients with some forms of nephrotic syndrome, IgA nephropathy, 


\section{5-178}
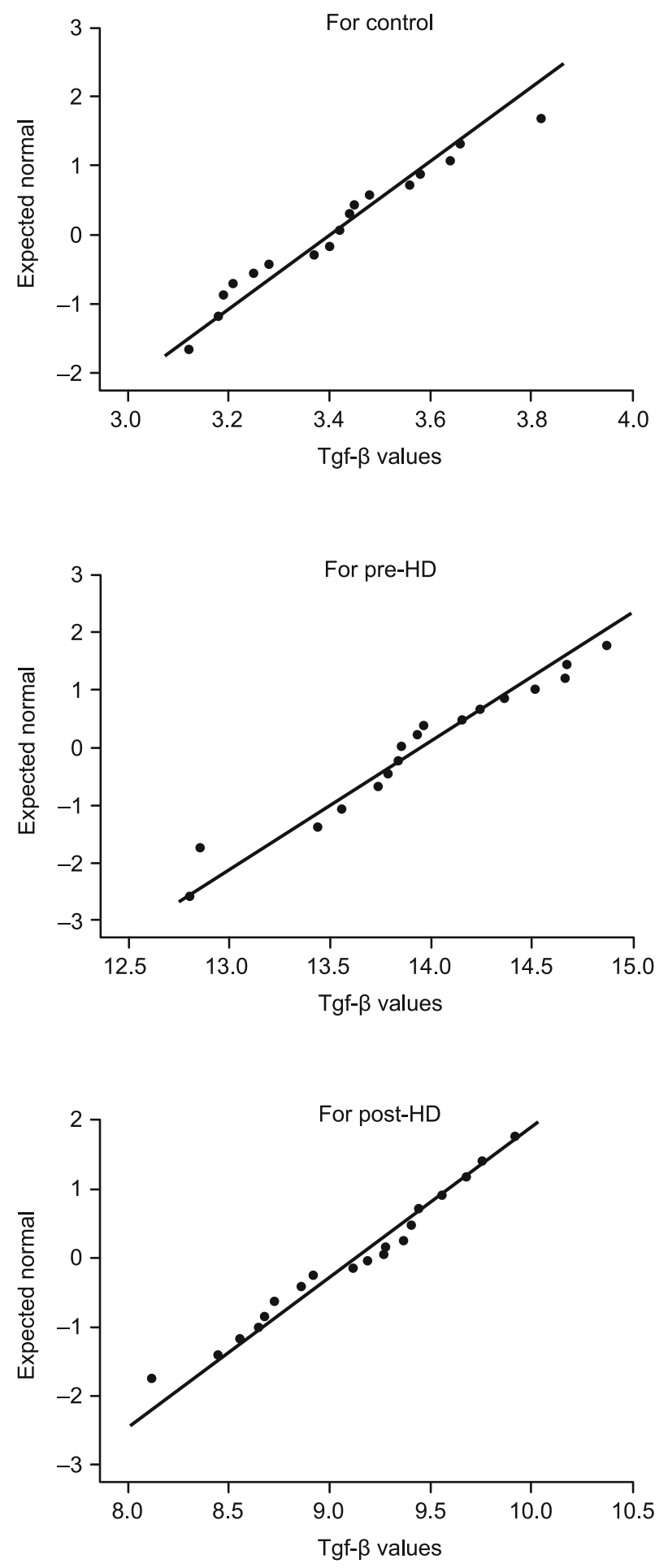

Fig. 1. Tgf- $\beta$ values in all groups (control, pre-HD, post-HD).

focal and segmental glomerulosclerosis, crescentic glomerulonephritis, lupus nephritis and diabetic nephropathy (18). Among the three TGF- $\beta$ isoforms, TGF- $\beta 1$ plays a key role in the pathogenesis of many forms of renal diseases. Increased TGF- $\beta 1$ levels correlate with progression of renal diseases. TGF- $\beta 1$ is the major activator

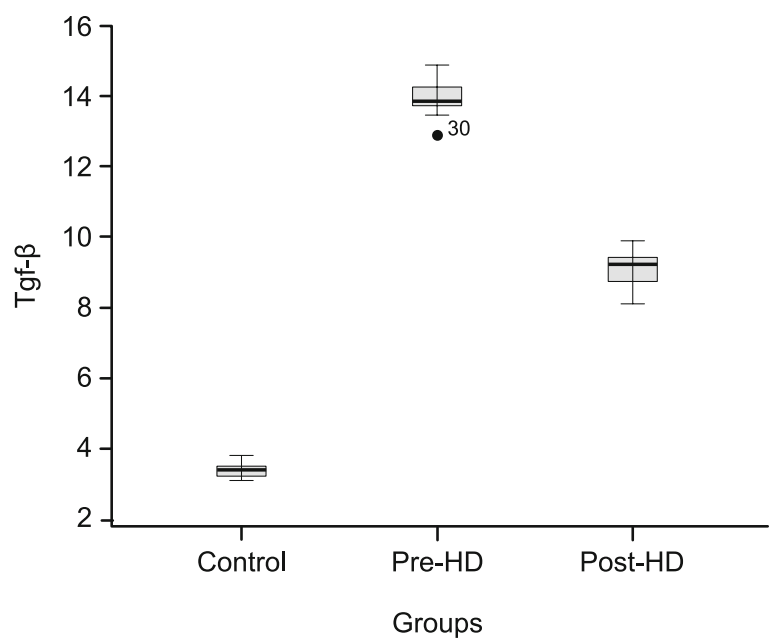

Fig. 2. Normal Q-Q Plot of TGF- $\beta$ values in all groups (control, preHD, post-HD).

of fibroblasts and this activation effect stimulates extracellular matrix $(\mathrm{ECM})$ production while inhibiting its degradation. TGF- $\beta 1$ also mediates renal diseases by inducing epithelial-mesenchymal transition involving tubular epithelial cells, which are speculated to contribute to the pathogenesis of tubular atrophy (12).

The purpose of this study was to evaluate the TGF beta-I levels in patients receiving hemodialysis treatment because of chronic renal failure.

\section{Materials and methods}

\section{Sample selection}

The patients who were dialyzed for 4 to $5 \mathrm{~h}$, three times per week, without diabetic nephropathy and treated with follow-up in the private dialysis centers in Corum and in 19 Mayis University Faculty of Medicine Hospital Nephrology Clinic were included in the investigation. The study was conducted in accordance with the guidelines of the Declaration of Helsinki and approved by the Ondokuz Mayis University Hospital Ethics Committee. The patients to whom dialysis has been applied were divided into two groups, the patients before and after dialysis. The healthy people who proved to be in a good state of health and free from any signs of chronic diseases or disorders were enrolled as a control group. A total of 68 samples were included in to the study. The patients and healthy individuals included in the study were grouped as follows.

Group I: serum samples of 20 healthy volunteers as control,

Group II: the serum samples taken before dialysis from 24 patients with diabetic nephropathy under the treatment of dialysis

Group III: the serum samples taken after dialysis from 24 patients with diabetic nephropathy under the treatment of dialysis

\section{Serum sample}

Serum and plasma were obtained by centrifugation of whole blood at $3000 \mathrm{rpm}$ for $10 \mathrm{~min}$ and aliquots were stored at $-20{ }^{\circ} \mathrm{C}$ until assayed (19). 
Determination of the Levels of TGF- $\beta 1$

Serum samples were assayed for circulating levels of active TGF- $\beta 1$ by enzyme linked immunosorbent assay (ELISA) technique. Commercially available high sensitive TGF- $\beta 1$ specific ELISA kit (Bendermed System Diagnostic, eBioscience, Austria, kit no: BMS249/3) was used. (Measuring wavelength: $450 \mathrm{~nm}$; reference wavelength: $620 \mathrm{~nm}$ ).

\section{Test procedure}

Reagents and Solutions prepare

Assay buffer concentrate (1X); $5 \mathrm{ml}$ Assay buffer (20x, PBS with $1 \%$ Tween-20 10\% BSA) $+95 \mathrm{ml}$ distilled water

Wash buffer concentrate (1X); $50 \mathrm{ml}$ Wash solution (20X, PBS with $1 \%$ Tween-20) $+950 \mathrm{ml}$ distilled water

Biotin conjugate; $120 \mu$ l Biotin conjugate $+11880 \mu$ l Assay buffer (1x)

Streptavidin - HRP; $120 \mu$ l Streptavidin - HRP $+11880 \mu 1$ Assay buffer (1x)

Substrate solution (tetramethyl- benzidine)

Stop solution (1M phosphoric acid)

Sample preparation

$180 \mu \mathrm{l}$ Assay buffer (1X) and $20 \mu \mathrm{l} 1 \mathrm{~N} \mathrm{HCl}$ were added to serum samples $(20 \mu \mathrm{l})$, vortexed and incubated for 1 hour. Then, $1 \mathrm{~N} \mathrm{NaOH}$ was added to samples and diluted $(1: 10)$.

Implementation of the Test Procedure

A TGF- $\beta 1$ standard curve was produced by a twofold serial dilution with final concentrations of $1000,500,250,125,62.5$, 32.5 and $15.16 \mathrm{pg} / \mathrm{ml}$ using a human TGF- $\beta 1$ standard.

Respectively, added $60 \mu 1$ of assay buffer to the sample wells and $40 \mu \mathrm{l}$ of each sample in duplicate to the sample wells. Covered with an adhesive film and incubated at room temperature ( 18 to $25^{\circ} \mathrm{C}$ ) for 1 hour. Then removed adhesive film and washed microwell strips 5 times with wash buffer $(400 \mu l)$. Then $100 \mu 1$ of streptavidin HRP was added and covered with an adhesive film and incubated at room temperature $\left(18\right.$ to $\left.25^{\circ} \mathrm{C}\right)$ for 1 hour. Microwell strips were washed 5 times with wash buffer $(400 \mu \mathrm{l})$ than $100 \mu \mathrm{l}$ amplification solution I was added, covered with an adhesive film and incubated at room temperature ( 18 to $25^{\circ} \mathrm{C}$ ) for $15 \mathrm{~min}$. The adhesive film was removed and washed in microwell strips 5 times with wash buffer $(400 \mu \mathrm{l})$. Than $100 \mu \mathrm{l}$ of TMB Substrate Solution was added to all wells and incubated the microwell strips at room temperature $\left(18^{\circ} \mathrm{C}\right.$ to $\left.25^{\circ} \mathrm{C}\right)$ for $15 \mathrm{~min}$ utes. Direct exposure to intense light was avoided. Then added the stop solution and the color development monitored by the ELISA reader at $620 \mathrm{~nm}$.

\section{Statistical analysis}

Statistical analysis was performed using the SPSS 20.0 software (SPSS Inc., Chicago, IL). All measurements were taken in triplicates. The results were expressed as mean $\pm \mathrm{SD}$. The critical significance level for the statistical tests performed was set to be 0.05 . After assessing the normality distribution (KolmogorovSmirnov and Shapiro-Wilk test) and homogeneity of variances of the data, One Way-Anova from parametric tests for comparison of differences among three groups was used.

\section{Results}

The serum level of total TGF- $\beta 1$ was $3.40 \pm 0.19 \mathrm{pg} / \mathrm{ml}$ in the control subjects. Serum TGF- $\beta 1$ levels were determined both before and after hemodialysis treatment from each patient. TGF- $\beta 1$ levels before and after hemodialysis treatment was found to be $13.97 \pm 0.45$ and $9.12 \pm 0.46 \mathrm{pg} / \mathrm{ml}$, respectively. The value of TGF- $\beta 1$ in serum was statistically significantly reduced after hemodialysis treatment but it was still higher than in the control groups $(\mathrm{p}<0.05)($ Tab. 1).

\section{Discussion}

The low inflammation is a general feature of chronic kidney disease (CKD) (20). Increases in some cytokines in patients with different values of kidney injury were previously reported (21). Morbidity and mortality rate is increasing due to systemic complications associated with renal failure patients who are developing ESRD. Morbidity and mortality risks increased depending on mainly cardiovascular events starting from early stages of CKD $(22,23)$. Studies have shown that mortality rate in dialysis patients is 10 to 30 times higher than in the general population $(24,25)$. More than 50 percent of deaths developed due to cardiovascular events. According to Kidney Registry System data of Turkish Nephrology Society (2012), 54 percent of hemodialysis patients and 57.1 percent of peritoneal dialysis patients are dying due to cardiovascular events in dialysis population in our country. Therefore, determination of each parameter in CKD patients is very important. TGF- $\beta$ is one of these parameters. Clinical evidence suggest that the response triggered by TGF- $\beta$ involves a final pathway leading to the development of renal diseases (26). It is stated that there is a positive association between the serum concentration of TGF- $\beta$ and a variety of established risk factors for CRF progression (27). Our data demonstrate that circulating levels of TGF- $\beta$ are higher in patients with chronic renal failure than in those of the control groups. Similar to our results Stefoni et al (2002) found higher levels of serum TGF- $\beta 1$ in ESRD patients than in those of the control groups and they showed that TGF- $\beta 1$ serum levels are significantly reduced after hemodialysis treatment (28).

In conclusion, the pathogenesis of CVD in CRF has a multifactorial basis yet evidence indicated that endothelial dysfunction has a very important role. Potential mechanism responsible for ED in CKD is oxidative stress. TGF- $\beta$ is a multifunctional cytokine that plays an important roles in oxidative stress due to developing

Tab. 1. Values of immune marker (TGF beta) of patients with COLD and control group and their $95 \%$ confidence intervals.

\begin{tabular}{lccc}
\hline Groups & $\begin{array}{c}\text { TGF- } \beta 1 \\
(\mathrm{pg} / \mathrm{ml})\end{array}$ & $\mathrm{n}$ & $\begin{array}{c}95 \% \text { CI } \\
(\text { Min. }- \text { Max. })\end{array}$ \\
\hline Control & $3.40 \pm 0.19$ & 20 & $3.32-3.49$ \\
Pre-HD & $13.97 \pm 0.45$ & 24 & $13.78-14.15$ \\
Post-HD & $9.12 \pm 0.46$ & 24 & $8.92-9.31$ \\
\hline
\end{tabular}

Mean \pm SD: is for each of the groups mean value and standard deviation; n: number of individuals; Pre-HD: Before hemodialysis; Post-HD: After hemodialysis; CI: Confidence interval for mean. 
of chronic renal failure. Our study shows that TGF- $\beta 1$ serum levels are higher in patients with chronic renal failure than those of control group. It is thought that increased oxidative stress causes the high TGF- $\beta 1$ levels in chronic diseases. Inducing cardiovascular events via ascended oxidative stress increases morbidity and mortality risks. Serum levels of TGF- $\beta 1$, which has high levels in these patients groups, are significantly reduced post-hemodialysis treatment. This result indicates hemodialysis is an effective treatment method to decrease the serum TGF-B1 levels. But this decrease is not sufficient enough to reduce existing risks.

\section{References}

1. Hwang SJ, Tsai JC, Chen HC. Epidemiology, impact and preventive care of chronic kidney disease in Taiwan. Nephrol 2010; 15: 3-9.

2. Levey AS, Atkins R, Coresh J. Chronic kidney disease as a global public health problem: approaches and initiatives - a position statement from kidney disease improving global outcomes. Kidney Int 2007; 72: 247-259.

3. August P, Sharma V, Ding R, Schwartz JE, Suthanthiran M. Transforming growth factor beta and excess burden of renal disease. Trans Am Clin Climatol Ass 2009; 120: 61-72.

4. Smyth A. End-Stage Renal Disease and Renal Replacement Therapy in older Patients. Nephrol Urol Mon 2012; 4-2: 425-430.

5. Roy-Chaudhury P, Sukhatme VP, Cheung AK. Hemodialysis vascular access dysfunction: a cellular andmolecular view point. J Am Soc Nephrol 2006; 17: 1112-1127.

6. Lee T, Roy-Chaudhury P. Advances and new frontiers in the pathophysiology of venous neointimal hyperplasia and dialysis access stenosis. Adv Chron Kidney Dis 2009; 16: 329-338.

7. Dember LM, Beck GJ, Allon M et al. Effect of clopidogrel on early failure of arteriovenous fistulas for hemodialysis. JAMA 2008; 299: $2164-2171$.

8. Stinkens R, Goossens GH, Jocken JW, Blaak EE. Targeting fatty acid metabolism to improve glucose metabolism. Obes Rev 2015; 16 (9): 715-57.

9. Beatty AL, Ku IA, Bibbins-Domingo K, Christenson RH, DeFilippi CR, Ganz $P$ et al. Traditional risk factors versus biomarkers for prediction of secondary events in patients with stable coronary heart disease: from the heart and soul study. J Am Heart Ass 2015; 4-7.

10. Kluppelholz B, Thorand B, Koenig W, de Las Heras Gala T, Meisinger $\mathbf{C}$, Huth $\mathbf{C}$ et al. Association of subclinical inflammation with deterioration of glycaemia before the diagnosis of type 2 diabetes: the KORA S4/F4 study. Diabetologia 2015; 58 (10): 2269-2277.

11. Esser N, Paquot N, Scheen AJ. Inflammatory markers and cardiometabolic diseases. Acta Clin Belg 2015; 70 (3): 193-199.

12. Lan HY. Diverse roles of TGF- $\beta /$ Smads in renal fibrosis and inflammation. Int J Biol Sci 2011; 7 (7): 1056-1067.

13. Lee SB, Kanasaki K, Kalluri R. Circulating TGF- $\beta 1$ as a reliable biomarker for chronic kidney disease progression in the African-American population. Kidney Int 2009; 76 (1): 10-12.
14. Tirado-Rodriguez B, Ortega E, Segura-Medina P, Huerta-Yepez S. TGF- $\beta$ : an important mediator of allergic disease and a molecule with dual activity in cancer development. J Immunol Res 2014; doi. org/10.1155/2014/318481.

15. Burks TN, Cohn RD. Role of TGF- $\beta$ signaling in inherited and acquired myopathies. Skel Musc 2011; 1: 19.

16. Loeffler I, Wolf G. Transforming growth factor- $\beta$ and the progression of renal disease. Nephrol Dial Transplant 2013.

17. Katre A, Ballinger C, Akhter H, Fanucchi M, Kim DK, Postlethwait E, Liu RM. Increased transforming growth factor beta 1 expression mediates ozone-induced airway fibrosis in mice. Inhal Toxicol 2011; 23 (8): 486-494.

18. Schnaper HW, Jandeska S, Runyan CE, Hubchak SC, Basu RK, Curley JF, Smith RD, Hayashida T. TGF-beta signal transduction in chronic kidney disease. Front Biosci (Landmark Ed) 2009; 1 (14): 2448-2465.

19. Avci E, Coşkun Ş, Çakir E, Kurt Y, Özgür Akgül E, Bilgi C. Relations Between Concentrations of Asymmetric Dimethylarginine and Neopterin as Potential Risk Factors for Cardiovascular Diseases in Haemodialysis-Treated Patients. Renal Failure 2008; 30 (8): 784-790.

20. Spoto B, Leonardis D, Parlongo RM et al. Plasma cytokines, glomerular filtration rate and adipose tissue cytokines gene expression in chronic kidney disease (CKD) patients Nutr Metab Cardiovasc Dis 2012; 22 (11): 981-988.

21. Descamps-Latscha B, Herbelin A, Nguyen AT et al. Balance between IL-1 beta, TNF-alpha, and their specific inhibitors in chronic renal failure and maintenance dialysis. Relationships with activation markers of T cells, B cells, and monocytes. J Immunol 1995; 154 (2): 882-892.

22. Go AS, Chertow GM, Fan D et al. Chronic kidney disease and the risks of death, cardiovascular events, and hospitalization. N Engl J Med 2004; 351: 1296-305.

23. U.S. Renal Data System, USRDS 2013 Annual Data Report: Atlas of End Stage Renal Disease in the United States. National Institutes of Health, National Institute of Diabetes and Digestive and Kidney Diseases, Bethesda, 2013.

24. Chronic Kidney Disease Prognosis Consortium. Association of estimated glomerular filtration rate and albuminuria with all-cause and cardiovascular mortality in general population cohorts: a collaborative metanalysis. Lancet 2010; 375: 2073-2081.

25. Foley RN, Parfrey PS, Sarnak MJ. Clinical epidemiology of cardiovascular disease in chronic renal failure. Am J Kidney Dis 1998; 32 (3): 112-119.

26. Border WA, Noble NA, Yamamoto T. Natural inhibitor of transforming growth factor- $\beta$ protects against scarring in experimental kidney disease. Nature 1992; 360 (6402): 361-364.

27. Suthanthiran M, Gerber LM, Schwartz JE. Circulating transforming growth factor- $\beta 1$ levels and the risk for kidney disease in African Americans. Kidney Int 2009; 76: 72-80.

28. Stefoni S, Cianciolo G, Donati G, Dormi A, Silvestri MG, Coli L, De Pascalis A, Iannelli S. Low TGF-beta1 serum levels are a risk factor for atherosclerosis disease in ESRD patients. Kidney Int 2002; 61 (1): 324-335.

Received November 24, 2016. Accepted December 5, 2016. 